\title{
$2-2015$
}

\section{Robust Multiple Regimes in Growth Volatility}

Andros Kourtellos

Ioanna Stylianou

Chih Ming Tan

University of North Dakota, chihming.tan@UND.edu

\section{How does access to this work benefit you? Let us know!}

Follow this and additional works at: https://commons.und.edu/ef-fac

Part of the Economics Commons

\section{Recommended Citation}

Andros Kourtellos, loanna Stylianou, and Chih Ming Tan. "Robust Multiple Regimes in Growth Volatility" (2015). Economics \& Finance Faculty Publications. 3.

https://commons.und.edu/ef-fac/3

This Article is brought to you for free and open access by the Department of Economics \& Finance at UND Scholarly Commons. It has been accepted for inclusion in Economics \& Finance Faculty Publications by an authorized administrator of UND Scholarly Commons. For more information, please contact und.commons@library.und.edu. 


\title{
Robust Multiple Regimes in Growth Volatility
}

\author{
Andros Kourtellos* $^{*}$ Ioanna Stylianou ${ }^{\dagger} \quad$ Chih Ming Tan ${ }^{\ddagger}$
}

February 27, 2014

\begin{abstract}
In this paper we uncover growth volatility regimes and identify their robust determinants using a large international panel of countries. In doing so we propose a novel empirical methodology that allows us to simultaneously deal with two key elements of model uncertainty, namely theory uncertainty and parameter heterogeneity, by unifying two recent econometric techniques: Bayesian Model Averaging and Threshold Regression. We find ample evidence of parameter heterogeneity and model uncertainty. Our results highlight the role of Ethnic Fractionalization, Institutions, Financial Development, Health, and Geography.
\end{abstract}

Keywords: growth volatility, multiple regimes, threshold regression.

JEL Classification Codes: C59, O40, Z12.

\footnotetext{
*Department of Economics, University of Cyprus, P.O. Box 537, CY 1678 Nicosia, Cyprus, e-mail: andros@ucy.ac.cy.

${ }^{\dagger}$ Department of Economics, University of Cyprus, P.O. Box 537, CY 1678 Nicosia, Cyprus, e-mail: sioanna@ucy.ac.cy .

${ }^{\ddagger}$ Department of Economics, University of North Dakota, 293 Centennial Drive Stop 8369, Grand Forks, North Dakota, USA
} 


\section{Introduction}

The seminal work of Ramey and Ramey (1995) on the adverse effects of volatility on economic growth has led to a considerable amount of interest in the need to understand the sources of growth volatility. Notable examples include Acemoglu, Johnson, Robinson, and Thaicharoen (2003) who find that institutions are a fundamental determinant of volatility through a number of microeconomic and macroeconomic channels, Mobarak (2005) who emphasizes the role of democracy in reducing growth instability, and Bekaert, Harvey, and Lundblad (2006) who provide strong evidence that financial liberalization is associated with lower growth volatility. More recently, Malik and Temple (2009) find an especially important role for geography since remote countries are more likely to have undiversified exports.

Despite all this work there is remarkably little consensus on which determinants are the most important sources of growth volatility. We posit that the major reason for this problem is that the existing empirical studies generally ignore model uncertainty that typically plague cross-country regressions. Therefore, the objective of this paper is to identify robust determinants of growth volatility by addressing two key facets of model uncertainty: parameter heterogeneity and theory uncertainty.

Parameter heterogeneity refers to the idea that the data generating process that describes the stochastic phenomenon of growth volatility is not common for all observations (countries). There are reasons to believe that different countries may follow different growth volatility processes. For example, countries that are facing structural adjustment issues; such as those experiencing particularly high debt-to-GDP ratios or hyper-inflation, may face greater financing constraints that reduce the ability of countries to smooth out income across time. Alternatively, policy instruments that aim to stabilize growth may have different effects for countries at different levels of development. While the issue of parameter heterogeneity in growth regressions has been investigated thoroughly by a number of papers, this issue has not been systematically addressed in growth volatility regressions.

One approach that deals with the problem of parameter heterogeneity is to use threshold regression models or classification algorithms such as a regression tree. These models classify observations into stochastic processes depending on whether the observed value of a threshold variable is above (or below) a sample split value (threshold parameter), which is estimated from the data. In a seminal paper, Durlauf and Johnson (1995) employed a regression tree approach to uncover multiple growth regimes in the data. Following a similar strategy 
Papageorgiou (2002) organized countries into multiple growth regimes using the trade share and Tan (2010) classified countries into development clubs using the average expropriation risk. ${ }^{1}$ More recently, Kourtellos, Stengos, and Tan (2013b) investigate the impact of public debt on economic growth using a threshold regression model that allows for an endogenous threshold variable.

The term theory uncertainty was first coined by Brock and Durlauf (2001) to refer to the idea that new growth theories are open-ended, which means that any given theory of growth does not logically exclude other theories from also being relevant. In the present context, theory uncertainty implies that in the empirical modeling of growth volatility there is no a priori justification for focusing on a specific subset of explanatory variables. For example while Di Giovanni and Levchenko (2009) emphasize the importance of trade openness as a growth volatility determinant, Acemoglu, Johnson, Robinson, and Thaicharoen (2003) argue that institutions is the main source of growth volatility. It is not clear if the correct model specification should include both theories, or just one (or none) of them, since the inclusion of one theory; e.g., trade openness, does not automatically preclude the other; e.g., institutions, from also being a determinant of growth volatility. However, the estimated partial effect, say, of any particular determinant on growth volatility may vary dramatically across model specifications. How should one deal with the dependence of inference on model specifications?

One way to deal with this problem is to employ Bayesian Model Averaging (BMA), which dates back to Leamer (1978), and was further studied by Draper (1995), Kass and Raftery (1995), and Raftery, Madigan, and Hoeting (1997). Model averaging constructs estimates that do not depend on a particular model specification but rather use information from all candidate models. In particular, it amounts to forming a weighted average of model specific estimates where the weights are given by the posterior model probabilities. BMA has been widely applied in growth regressions and has proven to be particularly useful in identifying robust growth determinants; see for example, Brock and Durlauf (2001), Fernandez, Ley, and Steel (2001), Sala-i Martin, Doppelhofer, and Miller (2004), Durlauf, Kourtellos, and Tan (2008), and Masanjala and Papageorgiou (2008). However, in the context of growth volatility the benefits of BMA have been largely ignored. A notable exception is the paper by Malik and Temple (2009) who employ BMA to identify structural determinants of output

\footnotetext{
${ }^{1}$ One difference is that Papageorgiou (2002) employs the threshold regression of Hansen (2000) while Tan (2010) employs a generalized regression tree algorithm.
} 
volatility in developing countries.

In this paper, we attempt to deal with both parameter heterogeneity and theory uncertainty in the growth volatility process by synthesizing threshold regression and model averaging methods. The existing literature either deals with model uncertainty in the linear context or attempts to systematically uncover possible nonlinearity/heterogeneity, but approaches that coherently address both problems at the same time have been lacking. Some initial attempts in this direction have been made by Brock and Durlauf (2001), Kourtellos, Tan, and Zhang (2007), and Cuaresma and Doppelhofer (2007). Our paper is closest in spirit to Brock and Durlauf (2001). Brock and Durlauf show in their paper how researchers can simultaneously address issues of parameter heterogeneity and theory uncertainty when the nature of the parameter heterogeneity is known. In the example in their paper, for instance, they model the a priori heterogeneity between the Sub-Saharan African growth process compared with that for the rest of the world to be given (known). Here, we treat the potential sources for parameter heterogeneity as unknown and conduct a series of tests for the existence of thresholds to identify the strongest evidence for sources of parameter heterogeneity from the set of growth volatility determinants. Once the source of parameter heterogeneity has been identified, we then proceed to investigate the robust determinants of growth volatility. Our methodology can be viewed as an extension of Brock and Durlauf (2001) in that we employ threshold regression models to estimate the multiple regimes and account for model uncertainty within and across various threshold regression models.

This paper is also related to several empirical growth papers that use semiparametric methods such as the varying coefficient model (e.g., Durlauf, Kourtellos, and Minkin (2001) and Mamuneas, Savvides, and Stengos (2006)) and the partial linear regression model (e.g., Liu and Stengos (1999) and Kalaitzidakis, Mamuneas, Savvides, and Stengos (2001)) to identify nonlinear growth patterns and model parameter heterogeneity in the cross-country growth process. More recently, Henderson, Papageorgiou, and Parmeter (2011) investigate the presence of nonlinearities in the cross-country growth process using non-parametric regression methods in a context that allows for model uncertainty. In particular, using a cross-validation procedure that smooths away the irrelevant variables they find that most individual growth theories are characterized by non-linearities and therefore empirical growth methods will benefit by incorporating such nonlinearities. Our paper can be viewed as an alternative methodology that focuses on abrupt as opposed to smooth nonlinearities. Moreover, the threshold regression model is a parsimonious specification that uses only an 
extra parameter and does not suffer from the curse of dimensionality problems that effect nonparametric methods.

In particular, we start by investigating the sources of growth volatility in the context of linear models using a BMA analysis. Our findings highlight the mitigating role of health via increased life expectancy in reducing growth volatility. This finding is consistent with that found in Bekaert, Harvey, and Lundblad (2006). If individuals expect to live longer then they potentially face higher returns to human and physical capital investments, and are incentivized to make these investments leading to lower volatility. Additionally, we find evidence that macroeconomic policy via trade openness and public debt increase growth volatility. These results are also consistent with the literature. As di Giovanni and Levchenko (2000) have argued, trade openness increases volatility in tradeable goods sectors of the economy and also reduces diversification in the economy by encouraging specialization. While they acknowledge that sectors that are open to trade are less correlated with other sectors of the economy and therefore trade openness also could lead to lower volatility, they find that empirically, the first two effects trump the latter. With regards to the positive relationship between public debt levels and volatility, Cecchetti, Mohanty, and Zampolli (2011) have argued that high levels of public debt make countries particularly vulnerable to shocks because of the response of economic agents to the higher probability of default.

Next, we investigate the presence of multiple growth volatility regimes using threshold regression models. First, we employ a testing strategy that uncovers the significant regimes for a range of threshold variables and then use BMA analysis within each regime to uncover the robust regime-specific sources of growth volatility. Our tests reveal substantial evidence for parameter heterogeneity over a range of plausible threshold variables. Notably, the quality of a countrys institutions and financial development appear to be among the most plausible explanations for the presence of growth volatility regimes.

Since life expectancy, trade openness, and public debt were identified in the linear BMA exercises to be robust determinants of growth volatility, we also examine the impact of these variables in the threshold context. Increased life expectancy tends to reduce volatility across all regimes defined by most threshold variables. However, our results reveal substantial heterogeneity in the effects of trade openness and public debt on volatility. Both of these macroeconomic policy variables appear to interact with a countrys financial development, institutions, degree of ethnic fractionalization, and levels of internal and external conflict to impact volatility. For instance, trade openness increases volatility only when the level of 
financial development is above a threshold level; the effect is insignificant otherwise. This result suggests that countries that are particularly open (to the flow of goods and capital) may also be particularly vulnerable to the effects of macroeconomic shocks. In another example, high levels of public debt do not translate into higher volatility in all cases. In fact, their effect is significant when the countrys institutions are particularly bad (below a threshold level). This result is related to Kourtellos, Stengos, and Tan (2013b) who find that the negative effect of public debt on growth can be found only for countries with bad institutions.

The paper is organized as follows. Section 2 describes the canonical linear growth volatility model and our data. Section 3 presents model averaging estimates of the linear growth volatility model. Section 4 describes the threshold growth regression model and presents the results. Finally, section 5, concludes.

\section{The canonical growth volatility model and data description}

Following the literature we define the volatility of economic growth, $\sigma_{g, i}$, as the standard deviation of the growth rate of real per capita GDP over five 5-year period time intervals sampled from 74 countries of the PWT 7.0 for 1985-89, 1990-94, 1995-99, 2000-04, and 2005$09{ }^{23}$ Then, using a pooled panel analysis the canonical growth volatility regression takes the form:

$$
\sigma_{g, i}=x_{i}^{\prime} \beta+u_{i}
$$

where $x_{i}$ is a $p \times 1$ vector of growth volatility determinants measured with a lag (i.e., sampled over the periods 1980-84, 1984-99, 1990-94, 1995-99, and 2000-04) and $u_{i}$ is an i.i.d. error term for $i=1,2, \ldots, N$. For robustness we also consider two alternative exercises. The first one replaces the 5 -year period lagged values of the determinants with their contemporaneous

\footnotetext{
${ }^{2}$ In the growth volatility literature there seems to be no consensus on the way to estimate the standard deviation. For example, while Acemoglu, Johnson, Robinson, and Thaicharoen (2003) use a 27-year time interval to estimate the standard deviation, Bekaert, Harvey, and Lundblad (2006) use 5 years.

${ }^{3}$ The data set includes 70 countries for 1980-84, 73 countries for 1985-89, and all 74 countries for the remaining periods.
} 
values. The second one employs a three 10-year period panel data set that allows for a more precise estimation of long run growth volatility, albeit with fewer pooled observations. All the robustness results are reported in Kourtellos, Stylianou, and Tan (2014) - henceforth, we will refer to this as the Online Appendix.

In the absence of strong theoretical guidance we follow the conventional practice and assume that the process of growth volatility shares the same information set as the process of economic growth. This suggest that the set of possible theories and their proxies that have been proposed in the empirical growth literature can also be used in the context of growth volatility. In particular, we consider determinants from 8 broad categories or theories of growth volatility: Solow growth theory, macroeconomic policy, institutions, finance, geography, ethnic fractionalization, health, and conflict.

We start with the Solow or Neoclassical growth variables, which include the logarithm of population growth plus 0.05 (Population Growth), the logarithm of the average investment to GDP ratio (Investments), the logarithm of the initial average years of secondary and tertiary schooling for male population over 25 years of age (Schooling), and the logarithm of the initial real GDP per worker (Initial Income). Theoretical work by Acemoglu and Zilibotti (1997) and Koren and Tenreyro (2007) suggest a negative relationship between growth volatility and initial income. Specifically, richer countries are less volatile because they are able to achieve a more balanced sectoral distribution of output.

As argued in Acemoglu, Johnson, Robinson, and Thaicharoen (2003) the traditional macroeconomic argument links growth volatility to bad macroeconomic policies. To account for the effect of macroeconomic policy on volatility we use the logarithm of average inflation rate (Inflation Rate), the standard deviation of the Inflation Rate (Inflation Volatility), the ratio of exports plus imports to GDP (Openness), the ratio of government consumption to GDP (Government), and the average public debt to GDP (Debt).

The literature has also documented the positive impact of financial liberalization and development on economic growth (e.g., Levine, Loayza, and Beck (2000) and McCaig and Stengos (2005)) and its negative impact on volatility (e.g., Bekaert, Harvey, and Lundblad (2006)). Following this literature we include two measures of financial (intermediary) development: (i) private credit by deposit money banks as a share of demand, time and saving deposits in deposit money banks $(B C B D)$ and (ii) the ratio of deposit money bank claims on domestic non-financial real sector to the sum of deposit money bank and Central 
Bank's claims on domestic non-financial real sector $(D B A C B A){ }^{4}$

Following the recent literature in economic growth that emphasizes the role of fundamental determinants we include variables that measure institutions, geography and climate, and ethnolinguistic fractionalization. For institutions we use six variables that proxy different aspects of a country's institutional quality as suggested by a number of papers in the literature; see for example Acemoglu, Johnson, Robinson, and Thaicharoen (2003), Mobarak (2005), and Bekaert, Harvey, and Lundblad (2006). In particular, we include the variable constraints placed on the executive (Executive Constraints), which measures institutional and other constraints that are placed on presidents and dictators (or monarchies). As argued by Acemoglu-et-al, countries with weak institutions are more likely to experience high volatility. Institutions; e.g., constraints on the executive, could potentially affect volatility in either direction. Effective constraints on executive discretion could result in less arbitrary shifts in policy and therefore reduce uncertainty and associated volatility. Alternatively, tight constraints on the executive might lead to an inability to respond flexibly to crises and/or policy deadlock resulting in higher levels of volatility. We also include a variable measuring the level of institutionalized democracy, which ranges from zero to ten where higher values equal a greater extent of institutionalized democracy. Additionally, we use Corruption, Law and Order, and Bureaucratic Quality. Finally, we control for the presence of political stability measured as the average of the first differences (in absolute values) of the Polity2 variable from Polity IV. The Polity2 variable is a measure of the degree of democracy in a country with a score of +10 representing most democratic and -10 signifying most autocratic.

Geographic and climatic characteristics have also been associated with growth volatility. Using a BMA methodology Malik and Temple (2009) found robust evidence that geographical characteristics of countries have effects on growth volatility. Therefore, we include both a climate variable and a geography variable. The climate variable is the percentage of a country's land area classified as tropical and subtropical via the Koeppen-Geiger system (Tropics) while the geography variable measures geographic isolation, which is proxied by the percentage of a country's land area within $100 \mathrm{~km}$ of an ice-free coast $(L C R 100 K M)$.

The role of ethnic fractionalization in economic growth has been documented by the growth literature. For example, Alesina, Baqir, and Easterly (1999) suggest that higher levels of ethnic heterogeneity can result in political disagreements over the provision

\footnotetext{
${ }^{4}$ We did not include any financial liberalization variables due to their unavailability for the time periods of our data.
} 
of public goods, and its subsequent under-provision. To control for the effects of ethnic fractionalization on growth volatility we use linguistic fractionalization (Language), which measures the shares of languages spoken as "mother tongues" due to Alesina, Devleeschauwer, Easterly, Kurlat, and Wacziarg (2003) as well as the International Country Risk Guide (ICRG) variables Religion Tensions and Ethnic Tensions that measure the degree of religion and ethnic tension, respectively.

Finally, following Bekaert, Harvey, and Lundblad (2006) we control for health and conflict. For health we use the average of life expectancy (Life Expectancy). For conflict we use two proxies. The first one measures the political violence in the country and its actual or potential impact on governance (Internal Conflict). The second one measures the risk to both the incumbent government and inward investment due to several conflict factors ranging from trade restrictions to a full-scale war (External Conflict).

Table 1 presents summary statistics for the pooled data. The variables are drawn from various sources. A detailed description of the variables and their sources is given in Table A1 of the Appendix.

\section{Model uncertainty in a linear world}

In this section we employ the BMA approach to identify robust determinants of growth volatility in equation (2.1). By robust we mean that our estimates do not condition on a specific choice of determinants but rather depend on a model space whose elements span an appropriate range of determinants suggested by a large body of work. The model space is denoted by $\mathcal{M}=\left\{\mathcal{M}_{1}, . ., \mathcal{M}_{M}\right\}$. Put differently, model averaging integrates out the uncertainty over models by taking the weighted average of model-specific estimates, where the weights $W=\left(w_{1}, \ldots, w_{M}\right)^{\prime}$, reflect the evidentiary support for each model given the data, $D$, and which are constructed to be analogous to posterior model probabilities.

In particular, the BMA estimator of $\beta$ takes the form of a weighted average of modelspecific LS coefficients estimates

$$
\widehat{\beta}_{B M A}^{\mathcal{M}}=\sum_{m=1}^{M} w_{m} \widehat{\beta}_{m} .
$$


with standard errors based on their corresponding model averaging variance estimator

$$
\widehat{V}_{B M A}^{\mathcal{M}}=\sum_{m=1}^{M} w_{k} \widehat{V}_{m}^{\beta}+\sum_{m=1}^{M} w_{m}\left(\widehat{\beta}_{m}-\widehat{\beta}_{B M A}^{\mathcal{M}}\right)^{2}
$$

where the first term captures the variance of the within model estimates and the second term captures the variance model-specific estimates across models. The latter is an additional source of variance, which does not arise when computing variances in the absence of model uncertainty. The notation $\widehat{\beta}_{B M A}^{\mathcal{M}}$ and $\widehat{V}_{B M A}^{\mathcal{M}}$ emphasizes the dependence of the estimator on the model space $\mathcal{M}$ instead of individual model $\mathcal{M}_{m}$.

The weights $W$ are given by the posterior model probabilities, which are computed using Bayes' rule, so that each weight is the product of the integrated likelihood of the data given a model and the prior probability for a model. As standard in the literature, we assume a uniform model prior so that the prior probability that any variable is included in the true model is taken to be 0.5; see for example Eicher, Papageorgiou, and Raftery (2011). Following Kass and Wasserman (1995) and Raftery (1995) we approximate the integrated likelihood of each model by the Bayesian information criterion (BIC). ${ }^{5}$

Our BMA approach is similar to that of Sala-i Martin, Doppelhofer, and Miller (2004) and Durlauf, Kourtellos, and Tan (2011) who employ a "hybrid" model averaging method in the sense that frequentist probability statements about observables given unobservables are mixed with Bayesian probability statement about unobservables given observables. So while $\widehat{\beta}_{B M A}^{\mathcal{M}}$ and $\widehat{V}_{B M A}^{\mathcal{M}}$ are effectively Bayesian objects, namely, the posterior mean and variance of $\beta$ given data, we report BMA posterior t-statistics for coefficient estimates and interpret them in the classical sense. ${ }^{6}$ Additionally, we also report the posterior probability of inclusion (PIP) for each regressor, which is a more standard way to conduct inference in the context of BMA. PIP is computed as the sum of posterior probabilities of the models, which contain that variable. Following Eicher, Henn, and Papageorgiou (2012) and Kass and Raftery (1995) we interpret the values of PIP as follows: PIP $<50 \%$ indicates lack of evidence for an effect, $50 \%<\mathrm{PIP}<75 \%$ indicates weak evidence for an effect, $75 \%<\mathrm{PIP}<95 \%$ indicates

\footnotetext{
${ }^{5}$ The BIC approximation to the integrated likelihood implicitly defines that the parameter prior is the unit information prior, which can be viewed as a special case of the Zellner's (fixed) g-prior that contains information approximately equal to that contained in a single observation.

${ }^{6} \mathrm{~A}$ caveat of this kind of inference is that the asymptotic distribution of the t-statistic is a mixture of Normal distributions, which is often characterized by irregular shapes, far away from Normal, and thereby rendering inference based on classical interpretations invalid.
} 
positive evidence for an effect, $95 \%<\mathrm{PIP}<99 \%$ indicates strong evidence for an effect, and $99 \%<\mathrm{PIP}<100 \%$ indicates decisive evidence for an effect.

\subsection{BMA results for the linear volatility growth model}

In this section we discuss the BMA findings for robust sources of growth volatility in the context of the linear volatility growth model in equation (2.1). Table 2 present the results from our model averaging analysis sorted by PIP, which is reported in the first column. The second and third columns present the BMA posterior means and standard errors for each covariate, respectively. The remaining four columns show LS results from two individual models: the posterior mode model and the full (or largest) model, which includes all variables that are included in the model space $\mathcal{M}$. Our reason for reporting the results from the posterior mode and full model is to provide the reader with the ability to compare findings via model selection - using the best model (in terms of posterior weights) or a low-bias model (at the cost of reduced efficiency) with potentially many irrelevant covariates - with those obtained via BMA.

Our BMA findings highlight the key role of life expectancy. In particular, consistent with the findings of Bekaert, Harvey, and Lundblad (2006) we find decisive evidence for the effect of Life Expectancy with PIP of about 0.99. The negative and significant posterior mean at $1 \%$ suggests that higher levels of life expectancy result in lower growth volatility. One interpretation of this effect is that the high probability of survival increases the incentives for human and physical capital accumulation, which in turn reduce growth volatility.

We also find positive evidence for the effect of Trade Openness and Debt with PIP's 0.83 and 0.91, respectively. Consistent with the findings of Kose, Terrones, and Prasad (2003) and Easterly, Islam, and Stiglitz (2000) the positive and significant posterior mean at $10 \%$ of Trade Openness on growth volatility suggests that more open economies are more vulnerable to external shocks. The effect of Debt on growth volatility also appears to be positive and statistically significant at $5 \%$, which implies the harmful role of public debt in creating volatility; see Cecchetti, Mohanty, and Zampolli (2011).

The BMA findings are confirmed by the results from the posterior mode and the full model. The posterior mode model includes all the model averaging covariates with statistically significant posterior mean. Interestingly, the posterior mode model also includes 
investments. Note, however, the posterior model probability for the mode model is 0.0530 , whereas the full model has posterior model probability of 0.000 suggesting that the latter is a rather poor model choice.

A careful look into the individual posterior model probabilities suggests that the posterior mode model is not a dominant model but rather the posterior mass is spread evenly, and over larger models, resulting in a high share of important covariates. For example, beyond the posterior mode, the next best four models carry probabilities $0.0250,0.0143$, 0.0126 , and 0.0103 .

In summing up our findings it is interesting to note that we do not find evidence that Solow variables, financial development, geography, and linguistic diversity affect growth volatility. Instead, we find a role for health via life expectancy and some macroeconomic policy via trade openness, and public debt.

It is important to realize that the above BMA findings are robust to the extent that the model space $\mathcal{M}$ is adequately specified. If growth volatility exhibits deep nonlinearities or parameter heterogeneity then the above BMA analysis in the context of linear models can fail to fully capture the model uncertainty and can yield misleading results. As argued in the introduction there are reasons to believe that different countries may exhibit different growth processes in a nonlinear way. This motivates us to investigate the threshold regression model that allows for parameter heterogeneity or nonlinearity in the following section.

Next we briefly describe the threshold regression model and propose a model averaging strategy that can account for parameter heterogeneity or nonlinearities.

\section{Model uncertainty in multiple growth volatility regimes}

\subsection{The threshold growth volatility model}

The threshold growth volatility model generalizes the linear model in equation (2.1) by

allowing for the presence of multiple growth volatility regimes. In particular, we employ the threshold regression (TR) model that sorts the data into two groups of observations, on the basis of some threshold variable $q_{s i}$, for $s=1, . ., r, r \leq p$, each of which obeys the same model. 
The key feature of this model is that it allows for an estimation of the threshold parameter (sample split) as well as the regression coefficients of the two regimes. This makes the model very appealing as it allows for increased flexibility in functional form and at the same time is not as susceptible to curse of dimensionality problems as nonparametric methods. Then, the TR can be described by the following two sub-sample regression equations

$$
\begin{aligned}
\sigma_{g, i}=\beta_{s 1}^{\prime} x_{i}+e_{s i}, & q_{s i} \leq \gamma_{s} \\
\sigma_{g, i}=\beta_{s 2}^{\prime} x_{i}+e_{s i}, & q_{s i}>\gamma_{s}
\end{aligned}
$$

where $\gamma_{s}$ is the scalar threshold parameter or sample split value and $\left(\beta_{s 1}^{\prime}, \beta_{s 2}^{\prime}\right)^{\prime}$ is the vector of regression coefficients for the low and high regime, respectively.

It is also customary to express the TR in a single equation by defining the indicator variable

$$
I\left(q_{s i} \leq \gamma_{s}\right)= \begin{cases}1 & \text { iff } q_{s i} \leq \gamma_{s}: \text { Regime } 1 \\ 0 & \text { iff } q_{s i}>\gamma_{s}: \text { Regime } 2\end{cases}
$$

and $I\left(q_{s i}>\gamma_{s}\right)=1-I\left(q_{s i} \leq \gamma_{s}\right)$. This yields

$$
\sigma_{g, i}=\beta_{s}^{\prime} x_{i}+\delta_{s}^{\prime} x_{i} I\left(q_{s i} \leq \gamma_{s}\right)+e_{s i}
$$

where $E\left(e_{s i} \mid x_{i}\right)=0, \delta_{s}=\beta_{s 1}-\beta_{s 2}$, and $\beta_{s}=\beta_{s 2}$. The parameter $\delta_{s}$ is interpreted as the threshold effect of $x_{i}$.

The statistical theory for this problem is provided by Hansen (2000) who proposed a concentrated least squares method for the estimation of the threshold parameter. The regression coefficients for the two regimes are obtained using LS on the two subsamples, separately. Under certain assumptions the asymptotic distribution of the threshold parameter $\gamma$ is nonstandard as it involves two independent Brownian motions. Finally, the confidence intervals for $\gamma$ are obtained by an inverted likelihood ratio approach.

\subsection{Model averaging results within the growth volatility regimes}

Estimation of the threshold growth volatility model requires decisions on the choice of the set of regressors $x_{i}$ and threshold variable $q_{i}$. Our strategy in this subsection fixes the set of plausible threshold variables and then for each threshold regression model it employs BMA 
within each regime to uncover robust and regime-specific growth volatility determinants. ${ }^{7}$

To decide the set of plausible threshold variables we employ a testing strategy for all the variables that were used as growth volatility determinants in equation (2.1). In particular, for each $q_{s i}, s=1, . ., p$, we test the null hypothesis of a linear model against the alternative of a threshold, $H_{0}: \delta_{s}=0$ vs. $H_{1}: \delta_{s} \neq 0$ and discard threshold variables that do not reject the null of the linear model at $10 \%$. We do so by employing the heteroskedasticity-consistent Lagrange multiplier (LM) test for a threshold of Hansen (1996). It is worth noting that inference in this context is not standard since the threshold parameter, $\gamma_{s}$, is not identified under the null hypothesis of a linear model (i.e. no threshold effect), and therefore the pvalues are computed by a bootstrap method. Specifically, the p-values are computed by a bootstrap that fixes the regressors from the right-hand side of equation (4.6) and generating the bootstrap dependent variable from the distribution $N\left(0, \widehat{e}_{i}^{2}\right)$, where $\widehat{e}_{i}$ is the residual from the estimated TR model.

Before we consider testing for threshold effects we first need to choose the set of relevant regressors. One possibility is to use the full set of growth volatility determinants that we considered in section 3.1. This may sound like a natural choice, especially since we plan to apply BMA within each regime subsequently. The problem with this solution is that the full model is a rather poor model in terms of posterior model probability, which may affect the inference in the threshold regression model. For example a poor model is likely to negatively affect the size and power of the threshold test. For this reason we focus on the set of robust regressors, denoted by $\breve{x}_{i}$, as determined by the rule of "PIP greater than $75 \%$ ". The set of robust regressors in this case includes Trade Openness, Life Expectancy, and Debt. For robustness purposes we also investigate models with regressors identified by the posterior mode model. In this case Investments are also added in the set of robust regressors $\breve{x}_{i}$. These robustness results are reported in the Online Appendix and show substantially similar findings.

Table 3 shows in the first columns the results of the threshold test when $\breve{x}_{i}$ is determined by the rule of "PIP greater than 75\%". Of the 25 potential candidates, 21 threshold variables appear as plausible threshold variables that sort the countries into two regimes at $10 \%$ size of the test.

\footnotetext{
${ }^{7}$ This approach is justified by the fact that the estimator of the threshold parameter is super-consistent while the regime-specific regression coefficient estimators are root-n consistent and thereby the latter can be estimated as if the threshold parameters were known; see for example Hansen (2000).
} 
More precisely, Schooling, Initial Income, Debt, Government, Executive Constraints, Bureaucratic Quality, Democracy, External Conflict, Corruption, Law and Order, Ethnic Tensions, BCBD, DBACBA, Life Expectancy, LCR100KM and Tropics, reject the null of the linear model at $1 \%$ size of the test. Additionally, Inflation Volatility, Internal Conflict, Religion Tensions and Language reject the null at 5\% size of the test and Inflation Rate reject the null at $10 \%$ size of the test.

The next five columns of Table 3 present results from the estimation of the corresponding threshold regression model including the threshold estimate, the confidence interval for the threshold parameter, the joint sum of squares (JSSE), and the sample sizes of the two regimes. For the models that reject the null at 10\%, Ethnic Tensions yields the lowest JSSE suggesting that it is the most plausible sample splitting variable if one uses the JSSE as a model selection criterion. The sample split of Ethnic Tensions at 0.8028 corresponds to New Zealand. Table A2 in the Appendix presents the countries sorted into the two regimes of Ethnic Tensions. Interestingly, when use the posterior mode model to determine the regressors in $\breve{x}_{i}$, we also find that the threshold regression model with the smallest JSSE is the one that uses Ethnic Tensions as a threshold variable.

Table 3 also shows that the differences in JSSE between the competing threshold models are rather small. But, does this imply that the actual country groupings are also similar? To answer this question we present in Table 4 the regime-specific sample means of growth volatility and the regressors of the threshold regression model. It appears that the sample means between the 'bad' and 'good' regimes are not very different. For instance, the sample of mean of growth volatility in the low democratic regime is 0.04180 while in the high inflation volatility regime the sample mean is 0.0429 , suggesting that the two groupings are not substantially different but rather the interpretation is different. Therefore, we choose to present the results for all 21 threshold regression models rather than focus only on the best model according to the JSSE criterion.

Table 5 shows the BMA results for the two regimes that correspond to each of the significant threshold variables when $\breve{x}_{i}$ is determined by the rule of "PIP greater than $75 \%$ " grouped by growth theory. In this case the set of robust determinants $\breve{x}_{i}$ includes Openness, Debt, and Life Expectancy. The columns show the regression coefficients for the low and high regimes for the each of the three robust determinants. All the threshold regression models include a constant and a trend but they are not reported to save space. We report the PPI, PM, and the LS coefficient of the full model. To save space we also do not report 
the corresponding standard errors but simply denote their significance with stars.

We first examine the effect of Openness on growth volatility. We find strong evidence for parameter heterogeneity. The evidence suggests that trade openness leads to higher volatility even for countries with good characteristics. Trade openness is associated with higher volatility even for initially richer countries, countries with deeper financial development, and countries with good macroeconomic policies (i.e., low levels of inflation and public debt). However, it is also true that countries experiencing internal tensions (i.e., higher degrees of ethnic and religious tensions and internal conflict) see a negative (in the sense of generating higher volatility) impact of trade openness on volatility. These effects are in general decisive with PIP close to $100 \%$ as well statistically significant at $1 \%$ for both the PM estimates of the BMA and the LS coefficients of the full model.

Our results therefore provide us with a richer and more nuanced view of the effect of trade openness on growth volatility. Trade openness is not globally negative for growth volatility. Its effects are insignificant for a large class of countries. Trade openness really only affects countries with a certain set of characteristics. In particular, relatively richer countries that are more open to trade and capital flows, but which exhibit internal risks in the form of political vulnerabilities due to internal divisions are particularly sensitive to the negative effects of trade openness. This more nuanced view also potentially rationalizes the mixed evidence found in the literature on the effects of trade on volatility. For example, while Mobarak (2005) finds that trade openness has a negative effect on volatility, Easterly, Islam, and Stiglitz (2000) find that openness contributes significantly to growth volatility. Given the findings in this paper, the mixed evidence can be understood as an implication of omitted parameter heterogeneity.

We obtain a similarly nuanced view for the effects of Debt on growth volatility. High levels of public debt are associated with higher levels of volatility for countries with lower levels of initial conditions (both human capital and income per capita), bad macroeconomic policies (high levels of inflation and public debt, and large government sectors), low quality institutions (low levels of executive constraints, bureaucratic quality, democracy, and rule of law and high risk of corruption), adverse geographical conditions (low geographic accessibility and closer to tropics), higher degrees of internal divisions (higher levels of ethnic and religious tensions), higher risk of conflict (both internal and external), and lower general health conditions (low life expectancy at birth). As pointed out in Kourtellos, Stengos, and Tan (2013b), much of the literature on the effects of public debt on economic performance has 
focused on identifying nonlinear effects of public debt. That is, the question has been whether there is a threshold level for public debt over which debt then has negative effects on growth and/or volatility. Kourtellos et al. investigated alternative explanations for the negative effects of high levels of public debt on growth. In the same spirit this paper seeks alternative explanations for the negative effects of excessive levels of public debt on volatility.

As we noted, Table 3 certainly shows that there is strong evidence that Debt is a potential threshold variable. Table 5 (Panel 6) also shows that for high levels of Debt, public debt is associated with higher levels of volatility. Hence, there is clearly evidence for debt nonlinearities. However, the above results suggest that we also cannot discard the possibility that the nature of the effect of debt on volatility is driven by the heterogeneous characteristics of countries. For example, perhaps public debt is only bad for volatility because countries that have low quality institutions or pursue ill-advised macroeconomic policies generate more tail-risks for creditors. Countries with better characteristics can sustain high levels of debt with fewer consequences. At this point, our results suggest that the data cannot distinguish between the two explanations (nonlinearity vs. heterogeneity), but it also suggests that we cannot dismiss either.

The results for Life Expectancy are more straightforward. In most cases, higher life expectancy results in lower growth volatility in both regimes regardless of the threshold variable. However, the magnitude of the effect generally differs both across threshold variables and between the low and high regimes for a given threshold variable. In addition, there is also evidence that the effect of life expectancy exhibits nonlinearity (see, Panel 18 of Table 5) highlighting the mitigating role of higher life expectancy in reducing volatility in the high Life Expectancy regime.

We finish this section with a caveat. The implicit assumption in our regime specific BMA analysis is that given a threshold variable $q_{s i}$, the threshold estimate, $\widehat{\gamma_{s}}$, based on the full set of regressors $\breve{x}_{i}$ is also a consistent estimate for all threshold regression models with regressors $\breve{x}_{m i}$ that belong to the model space $\breve{\mathcal{M}}$ spanned by the set of regressors $\breve{x}_{i}$. The justification for this approach is based on a corollary in Kourtellos, Stengos, and Tan (2013a), which says that when the constraints are valid the estimated threshold parameter for both the constrained and unconstrained problem will converge to the same true value. In our context the unconstrained model is the threshold regression model based on the full set of regressors $\breve{x}_{i}$ and the constrained models are the ones based on any $\breve{x}_{m i} \in \breve{\mathcal{M}}$. 


\section{Conclusion}

In this paper we uncover growth volatility regimes and identify their robust determinants using a large international panel of countries. In order to account for both theory uncertainty and parameter heterogeneity we propose an econometric modeling that unifies two econometric techniques: Bayesian Model Averaging and Threshold Regression.

We start by investigating the sources of growth volatility among linear models using a BMA analysis. Our results emphasize the decisive role of life expectancy in reducing volatility but also find substantial evidence for the positive effects of public debt and trade openness.

We then shift our focus to modeling parameter heterogeneity in the growth volatility process by investigating the presence of multiple regimes using threshold regression models. First, we test for the presence of a threshold effect using a range of threshold variables and then use BMA analysis within each regime to uncover the robust regime-specific sources of growth volatility. Our tests reveal substantial evidence for parameter heterogeneity over a range of plausible threshold variables including proxies for the growth theories of Ethnic Fractionalization, Institutions, Financial Development, Health, and Geography. Moreover, Ethnic Tensions, Initial Income, and Law and Order appear to be among the most plausible explanations for the presence of growth volatility regimes.

Our regime specific BMA analysis shows that there exists substantial heterogeneity in the effects of trade openness and public debt on growth volatility. Our results provide a more nuanced view of the effects of these key determinants on economic performance (volatility, in this case). Their effects are not global but most strongly affect countries with particular characteristics.

Finally, our results should not be interpreted as strong structural claims but rather as evidence that can help policy makers enhance their understanding of the sources of growth volatility. 


\section{References}

Acemoglu, Daron, R. Johnson, Simon, James Robinson, and Yunyong Thaicharoen, 2003, Institutional causes, macroeconomic symptoms: volatility, crises and growth, Journal of Monetary Economics 50, 49-123.

Acemoglu, D., and F. Zilibotti, 1997, Was prometheus unbound by chance? risk, diversification and growth., Journal of Political Economy 105, 1167-1200.

Alesina, A., R. Baqir, and W. Easterly, 1999, Public goods and ethnic divisions, Quarterly Journal of Economics 114, 1243-1284.

Alesina, A., A. Devleeschauwer, W. Easterly, S. Kurlat, and R. Wacziarg, 2003, Fractionalization, Journal of Economic Growth 8, 155-194.

Barro, R., and J.-L. Lee, 2013, A New Data Set of Educational Attainment in the World,19502010, Journal of Development Economics 104, 184-198.

Beck, T., A. Demirgüç-Kunt, and R. Levine, 2009, Financial institutions and markets across countries and over time: Data and analysis, World Bank Policy Research Working Paper 4943.

Bekaert, Geert, R. Harvey, Campbell, and Christian Lundblad, 2006, Growth volatility and financial liberalization, Journal of International Money and Finance 92, 370-403.

Brock, W., and S. D. Durlauf, 2001, Growth Empirics and Reality, World Bank Economic Review 15, 229-272.

Cecchetti, S., M. Mohanty, and F. Zampolli, 2011, The Future of Public Debt, in S. Gokarn, ed.: Challenges to central banking in the context of the financial crisis . pp. 183-217 (Academic Foundation: New Delhi).

Cuaresma, C. J., and G. Doppelhofer, 2007, Nonlinearities in cross-country growth regressions: A bayesian averaging of thresholds (bat) approach, Journal of Macroeconomics 29, 541-554.

di Giovanni, J., and A. A. Levchenko, 2000, Trade Openness and Volatility, Review of Economics and Statistics 91, 558-585. 
Di Giovanni, J., and A. A. Levchenko, 2009, Trade openness and volatility, The Review of Economics and Statistics 91, 558-585.

Draper, D., 1995, The geography of output volatility, Journal of the Royal Statistical Society, Series B 57, 45-97.

Durlauf, S., and P. Johnson, 1995, Multiple regimes and cross-country growth behavior, Journal of Applied Econometrics 10, 365-384.

Durlauf, S., A. Kourtellos, and A. Minkin, 2001, The Local Solow Growth Model, European Economic Review 15, 928-940.

Durlauf, S.N., A. Kourtellos, and C.M. Tan, 2011, Is God in the Details? A Reexamination of the Role of Religion in Economic Growth, Journal of Applied Econometrics, forthcoming.

Durlauf, S. N., A. Kourtellos, and C. M. Tan, 2008, Are Any Growth Theories Robust?, Economic Journal 118, 329-346.

Easterly, W., R. Islam, and J. E. Stiglitz, 2000, Shaken and Stirred: Explaining Growth Volatility, Annual World Bank Conference on Development Economics pp. 191-211.

Eicher, T., C. Henn, and C. Papageorgiou, 2012, Trade Creation and Diversion Revisted: Accounting for Model Uncertainty and Natural Trading Partner Effects, Journal of Applied Econometrics 27, 296-321.

Eicher, T., C. Papageorgiou, and A. E. Raftery, 2011, Default Priors And Predictive Performance In Bayesian Model Averaging, With Application To Growth Determinants, Journal of Applied Econometrics 26, 30-55.

Fernandez, C., E. Ley, and M. Steel, 2001, Model Uncertainty in Cross-Country Growth Regressions, Journal of Applied Econometrics 16, 563-576.

Hansen, B., 2000, Sample splitting and threshold estimation, Econometrica 68, 575-603.

Hansen, B. E., 1996, Inference when a nuisance parameter is not identified under the null hypothesis, Econometrica 64, 413-430.

Henderson, J., C. Papageorgiou, and C. F. Parmeter, 2011, Growth Empirics Without Parameters, The Economic Journal 122, 125-154. 
Kalaitzidakis, P., T. P. Mamuneas, A. Savvides, and T. Stengos, 2001, Measures of Human Capital and Nonlinearities in Economic Growth, Journal of Economic Growth 6, 229-254.

Kass, R., and L. Wasserman, 1995, A reference bayesian rest for nested hypotheses and its relationship to the schwarz criterion, Journal of the American Statistical Association 90, 928-934.

Kass, R. E., and A. E. Raftery, 1995, Bayes Factors, Journal of the American Statistical Association 90, 773-795.

Koren, M., and S Tenreyro, 2007, Volatility and development, Quarterly Journal of Economics 122, 243-287.

Kose, M. A., M. Terrones, and E. Prasad, 2003, Volatility and Comovement in a Globalized World Economy: An Empirical Exploration, IMF Working Papers with number 03/246.

Kourtellos, A., A. Stengos, and C. M. Tan, 2013a, Structural threshold regression, Working paper, University of Cyprus, Clark University, and University of Guelph.

Kourtellos, A., T. Stengos, and C. M. Tan, 2013b, The Effect Public Debt on Growth in Multiple Regimes, Journal of Macroeconomics 38, 35-43.

Kourtellos, A., I. Stylianou, and C. M. Tan, 2014, Robust Multiple Regimes in Growth Volatility - Online Appendix, University of Cyprus, Working Papers Series, https: //sites.google.com/site/kourtellos/.

Kourtellos, A., C. M. Tan, and X. Zhang, 2007, Is the relationship between aid and economic growth nonlinear?, Journal of Macroeconomics 29, 515-540.

Leamer, E. E., 1978, Specification Searches (Wiley, New York.).

Levine, R., N. Loayza, and T. Beck, 2000, Financial intermediation and growth: causality and causes, Journal of Monetary Economics 46, 31-77.

Liu, C., and T. Stengos, 1999, Non-linearities in Cross-Country Growth regressions: A Semiparametric Approach, Journal of Applied Econometrics 14, 527-538.

Malik, Adeel, and Jonathan R. W. Temple, 2009, The geography of output volatility, Journal of Development Economics 90, 163-178. 
Mamuneas, T., A. Savvides, and T. Stengos, 2006, Economic development and the return to human capital: A smooth coefficient semiparametric approach, Journal of Applied Econometrics 21, 111-132.

Masanjala, W., and C. Papageorgiou, 2008, Rough and Lonely Road to Prosperity: A Reexamination of the Sources of Growth in Africa Using Bayesian Model Averaging, Journal of Applied Econometrics 23, 671-682.

McCaig, B., and T. Stengos, 2005, Financial intermediation and growth: Some robustness results, Economics Letters 88, 306-312.

Mobarak, A. M., 2005, Democracy, volatility, and economic development, The Review of Economics and Statistics 87, 348-361.

Papageorgiou, C., 2002, Trade as a threshold variable for multiple regimes, Economics Letters $77,85-91$.

Raftery, A., D. Madigan, and J. Hoeting, 1997, Bayesian model averaging for linear regression models, Journal of the American Statistical Association 92, 179191.

Raftery, A. E., 1995, Bayesian Model Selection in Social Research (with Discussion), Sociological Methodology 25, 111-196.

Ramey, G., and V. Ramey, 1995, Cross-country evidence on the link between volatility and growth, American Economic Review 85, 1138-1151.

Sala-i Martin, X., G. Doppelhofer, and R. Miller, 2004, Determinants of Long-term Growth: a Bayesian Averaging of Classical Estimates (BACE) Approach, American Economic Review 94, 813-835.

Tan, C. M., 2010, No one true path: Uncovering the interplay between geography, institutions, and fractionalization in economic development, Journal of Applied Econometrics 25, 11001127. 


\section{Table 1: Descriptive Statistics}

$\begin{array}{lllll}\text { Variable } & \text { Mean } & \text { Std. Dev. } & \text { Min } & \text { Max } \\ \text { Growth Volatility } & 0.0337 & 0.0265 & 0.0031 & 0.1746 \\ \text { Population Growth } & -2.7218 & 0.1706 & -3.4129 & -2.2768 \\ \text { Investments } & 3.0338 & 0.3917 & 0.8104 & 4.0862 \\ \text { Schooling } & 0.6322 & 0.7363 & -2.4161 & 1.9588 \\ \text { Initial Income } & 8.5877 & 1.1932 & 6.1649 & 10.711 \\ \text { Inflation Volatility } & 45.605 & 347.2624 & 0.0675 & 5488.02 \\ \text { Inflation rate } & 2.2504 & 1.1563 & -0.8462 & 7.8335 \\ \text { Government } & 2.1919 & 0.4275 & 1.0779 & 3.1080 \\ \text { Openness } & 62.8959 & 34.2447 & 10.0729 & 192.91 \\ \text { Debt } & 73.7224 & 63.2664 & 4.2206 & 665.17 \\ \text { BCBD } & 0.9851 & 0.3967 & 0.1736 & 3.0004 \\ \text { DBACBA } & 0.7927 & 0.1974 & 0.1007 & 0.9994 \\ \text { Executive Constraints } & 0.6708 & 0.3522 & 0.0000 & 1.0000 \\ \text { Bureaucratic Quality } & 0.5925 & 0.2980 & 0.0000 & 1.0000 \\ \text { Democracy } & 5.8968 & 3.9814 & 0.0000 & 10.000 \\ \text { Corruption } & 0.5561 & 0.2289 & 0.0000 & 1.0000 \\ \text { Law and Order } & 0.6042 & 0.2536 & 0.1278 & 1.0000 \\ \text { Political Stability } & 0.3819 & 0.8500 & 0.0000 & 5.2000 \\ \text { LCR100KM } & 0.5094 & 0.3552 & 0.0000 & 1.0000 \\ \text { Tropics } & 0.4158 & 0.4353 & 0.0000 & 1.0000 \\ \text { Language } & 0.3698 & 0.3041 & 0.0021 & 0.8980 \\ \text { Ethnic Tensions } & 0.6643 & 0.2447 & 0.1111 & 1.0000 \\ \text { Religion Tensions } & 0.7540 & 0.2284 & 0.0028 & 1.0000 \\ \text { Life Expectancy } & 66.770 & 10.0303 & 37.8081 & 81.569 \\ \text { External Conflict } & 0.8093 & 0.1801 & 0.1486 & 1.0000 \\ \text { Internal Conflict } & 0.7189 & 0.2041 & 0.0611 & 1.0000\end{array}$




\section{Table 2: BMA results for the linear volatility growth model}

This table presents BMA results for the linear growth volatility model in equation (2.1). The first column shows the posterior inclusion probability (PIP), which is the sum of posterior model probablities over all those models that contain that variable. The posterior mean (PM) is the average of the LS coefficient estimates (COEF) of individual models weighted by the posterior model probability. The posterior standard error (PSE) is the BMA estimate for the standard error (SE). The last four columns report LS estimates of two individual models: the posterior mode model and the full model. All specifications always include an intercept and a time trend. ${ }^{* * *},{ }^{* *}$, and ${ }^{*}$ denote significance at $1 \%, 5 \%$, and $10 \%$, respectively.

Determinants
Solow
Population Growth
Investments
Schooling
Initial Income
Macroeconomic Policy
Inflation Volatility
Inflation Rate
Government
Openness
Debt

Financial Development

BCBD

DBACBA

Institutions

Executive Constraints

Bureaucratic Quality

Democracy

Corruption

Law and Order

Political Stability

Geography and Climate

LCR100KM

Tropics

Ethnic Fractionalization

Language

Ethnic Tensions

Religion Tensions

Health

Life Expectancy

Conflict

Internal Conflict

External Conflict

\begin{tabular}{ccc}
\multicolumn{3}{c}{ Model Averaging } \\
PIP & PM & PSE \\
& & \\
0.0573 & 0.0002 & 0.0027 \\
0.7000 & 0.0072 & 0.0056 \\
0.2090 & -0.0009 & 0.0023 \\
0.1333 & 0.0006 & 0.0017
\end{tabular}

0.1917

0.3447

0.0000

0.0000

0.2063

0.8273

0.9083

$-0.0009$

$0.0001^{*}$

$0.0001^{* *}$

0.1213

$-0.0002$

$-0.0019$

0.0013

0.0063

0.0847

0.0000

0.0019

0.0487

0.0000

0.0017

0.0260

0.0000

0.0001

0.2247

$-0.0028$

0.0066

0.0687

0.0001

0.0025

0.0443

0.0000

0.0620

0.0001

0.0012

0.0443

0.0001

0.0009

0.2273

$-0.0026$

0.0055

0.1897

0.0023

0.0055

0.0507

0.0001

0.0016

$0.9917-0.0010^{* * *} \quad 0.0003$

$-0.0010^{* * *} \quad 0.0002$

$\begin{array}{lll}0.0857 & 0.0006 & 0.0037\end{array}$

$\begin{array}{lll}0.1517 & -0.0020 & 0.0058\end{array}$
$-0.0013^{* * *}$

0.0004

\begin{tabular}{|c|c|c|c|}
\hline \multicolumn{2}{|c|}{ Posterior Mode } & \multicolumn{2}{|c|}{ Full } \\
\hline $\mathrm{COEF}$ & SE & $\mathrm{COEF}$ & $\mathrm{SE}$ \\
\hline & & 0.0077 & 0.0146 \\
\hline $0.0096^{* * *}$ & 0.0036 & & $\begin{array}{l}0.0045 \\
0.0034\end{array}$ \\
\hline & & $0.0057^{*}$ & 0.0032 \\
\hline
\end{tabular}

$0.0000^{* *} \quad 0.0000$

$0.0034^{* *} \quad 0.0015$

$-0.0056^{*} \quad 0.0033$

$0.0001^{* *} \quad 0.0001$

$0.0001^{* * *} \quad 0.0000$

$\begin{array}{ll}-0.0003 & 0.0033\end{array}$

$-0.0079 \quad 0.0119$

$\begin{array}{cc}0.0013 & 0.0190 \\ 0.0030 & 0.0086 \\ 0.0003 & 0.0017 \\ -0.0152 & 0.0115 \\ 0.0077 & 0.0114 \\ -0.0008 & 0.0014\end{array}$

$-0.0007 \quad 0.0051$

$0.0025 \quad 0.0051$

$-0.0066 \quad 0.0066$

$0.0093 \quad 0.0084$

$\begin{array}{ll}-0.0014 & 0.0073\end{array}$

$0.0053 \quad 0.0124$

$-0.0174^{*} \quad 0.0105$ 


\section{Table 3: Threshold tests and threshold estimates}

This table presents the threshold tests and threshold estimates. It reports the bootstrap p-value for the test of the null hypothesis of the linear growth volatility (2.1) against the alternative hypothesis of the threshold model in equation (4.6) using alternative threshold variables (one at a time) as indicated by each row. ***, $* *$, and $*$ denote significance of the threshold effect at 1\%, 5\%, and 10\%, respectively, as implied by the p-value. All underlying models were based on the full vector of regressors that included a constant, a trend, Life Expectancy, Openness, and Debt. The last four columns present the corresponding threshold estimate, $90 \%$ confidence intervals for the threshold parameter $\gamma$, the joint sum of squares (JSSE), and the sample size of the sub-samples.

\begin{tabular}{|c|c|c|c|c|c|c|}
\hline Threshold variable & p-value & Threshold Estimate & $90 \%$ C.I. & JSSE & $n_{1}$ & $n_{2}$ \\
\hline \multicolumn{7}{|l|}{ Solow } \\
\hline Population Growth & 0.3890 & -2.9014 & {$[-2.9194,-2.5482]$} & 0.1963 & 71 & 294 \\
\hline Investments & 0.1860 & 2.8689 & {$[2.7016,3.3841]$} & 0.1956 & 111 & 254 \\
\hline Schooling & $0.0000^{* * *}$ & 0.6515 & {$[-0.0255,1.4262]$} & 0.1897 & 176 & 189 \\
\hline Initial Income & $0.0000^{* * *}$ & 8.6340 & {$[7.0956,10.0710]$} & 0.1840 & 186 & 179 \\
\hline \multicolumn{7}{|l|}{ Macroeconomic Policy } \\
\hline Inflation Volatility & $0.0380^{* *}$ & 5.9386 & {$[1.0965,13.3535]$} & 0.1944 & 234 & 131 \\
\hline Inflation Rate & $0.0540^{*}$ & 2.1558 & {$[1.2609,3.1500]$} & 0.1940 & 180 & 185 \\
\hline Government & $0.0080^{* * *}$ & 2.1890 & {$[1.7108,2.6556]$} & 0.1867 & 170 & 195 \\
\hline Openness & 0.2490 & 58.8923 & {$[30.9846,99.4150]$} & 0.1977 & 202 & 163 \\
\hline Debt & $0.0000^{* * *}$ & 78.2945 & {$[32.4425,106.363]$} & 0.1876 & 247 & 118 \\
\hline \multicolumn{7}{|l|}{ Financial Development } \\
\hline $\mathrm{BCBD}$ & $0.0000^{* * *}$ & 0.6099 & {$[0.6014,1.3561]$} & 0.1852 & 55 & 310 \\
\hline DBACBA & $0.0000^{* * *}$ & 0.8318 & {$[0.5851,0.9775]$} & 0.1898 & 174 & 191 \\
\hline \multicolumn{7}{|l|}{ Institutions } \\
\hline Executive Constraints & $0.0000^{* * *}$ & 0.6667 & {$[0.1667,0.9667]$} & 0.1911 & 168 & 197 \\
\hline Bureaucratic Quality & $0.0000^{* * *}$ & 0.7000 & {$[0.2500,0.9979]$} & 0.1885 & 213 & 152 \\
\hline Democracy & $0.0000^{* * *}$ & 5.6000 & {$[0.0000,9.6000]$} & 0.1877 & 143 & 222 \\
\hline Corruption & $0.0010^{* * *}$ & 0.7167 & {$[0.3333,0.8250]$} & 0.1945 & 277 & 88 \\
\hline Law and Order & $0.0010^{* * *}$ & 0.6361 & {$[0.3333,0.9944]$} & 0.1843 & 196 & 169 \\
\hline Political Stability & 0.1970 & 0.2000 & {$[0.0000,0.6000]$} & 0.1955 & 280 & 85 \\
\hline \multicolumn{7}{|l|}{ Geography and Climate } \\
\hline Tropics & $0.0010^{* * *}$ & 0.0013 & {$[0.0000,0.9926]$} & 0.1908 & 158 & 207 \\
\hline LCR100KM & $0.0000^{* * *}$ & 0.5821 & {$[0.1098,0.9922]$} & 0.1930 & 220 & 145 \\
\hline \multicolumn{7}{|l|}{ Ethnic Fractionalization } \\
\hline Language & $0.0360^{* *}$ & 0.3962 & {$[0.0468,0.7680]$} & 0.1968 & 205 & 160 \\
\hline Ethnic Tensions & $0.0010^{* * *}$ & 0.8028 & {$[0.3444,0.9667]$} & 0.1824 & 222 & 143 \\
\hline Religion Tensions & $0.0290^{* *}$ & 0.8556 & {$[0.4778,0.9833]$} & 0.1969 & 254 & 111 \\
\hline \multicolumn{7}{|l|}{ Health } \\
\hline Life Expectancy & $0.0000^{* * *}$ & 66.8759 & {$[54.4005,76.8134]$} & 0.1890 & 144 & 221 \\
\hline \multicolumn{7}{|l|}{ Conflict } \\
\hline Internal Conflict & $0.0130^{* *}$ & 0.9174 & {$[0.4944,0.9389]$} & 0.1867 & 299 & 66 \\
\hline External Conflict & $0.0000 * * *$ & 0.9792 & {$[0.6153,0.9972]$} & 0.1950 & 288 & 77 \\
\hline
\end{tabular}




\section{Table 4: Sample means of the growth volatility regimes}

This table presents the sample means for Growth Volatility, Openness, Life Expectancy, and Debt in the low and high regimes that were identified by the various threshold regression models.

\begin{tabular}{|c|c|c|c|c|c|c|c|c|}
\hline \multirow[b]{2}{*}{ Threshold Variable } & \multicolumn{2}{|c|}{ Growth Volatility } & \multicolumn{2}{|c|}{ Openness } & \multicolumn{2}{|c|}{ Life Expectancy } & \multicolumn{2}{|c|}{ Debt } \\
\hline & Low & High & Low & High & Low & High & Low & High \\
\hline & \multicolumn{8}{|c|}{ Solow } \\
\hline Schooling & 0.0408 & 0.0271 & 61.5679 & 64.1325 & 60.5726 & 72.5414 & 80.9908 & 66.9541 \\
\hline \multirow[t]{2}{*}{ Initial Income } & 0.0377 & 0.0296 & 63.5192 & 62.2482 & 60.1916 & 73.6059 & 87.1976 & 59.7203 \\
\hline & \multicolumn{8}{|c|}{ Macroeconomic policy } \\
\hline Inflation Volatility & 0.0286 & 0.0429 & 62.2461 & 64.0565 & 69.3237 & 62.2088 & 64.2063 & 90.7208 \\
\hline Inflation Rate & 0.0290 & 0.0384 & 69.7257 & 56.2506 & 69.1791 & 64.4262 & 70.1604 & 77.1882 \\
\hline Government & 0.0340 & 0.0335 & 61.4522 & 64.1544 & 66.8036 & 66.7409 & 62.4959 & 83.5097 \\
\hline \multirow[t]{2}{*}{ Debt } & 0.0316 & 0.0381 & 60.3168 & 68.2945 & 68.4300 & 63.2956 & 47.7476 & 128.0936 \\
\hline & \multicolumn{8}{|c|}{ Financial Development } \\
\hline $\mathrm{BCBD}$ & 0.0505 & 0.0307 & 62.3521 & 62.9923 & 60.1508 & 67.9445 & 128.1041 & 64.0741 \\
\hline \multirow[t]{2}{*}{ DBACBA } & 0.0388 & 0.0291 & 61.9630 & 63.7457 & 61.1353 & 71.9034 & 93.5909 & 55.6224 \\
\hline & \multicolumn{8}{|c|}{ Institutions } \\
\hline Executive Constraints & 0.0406 & 0.0279 & 66.1887 & 60.0877 & 59.9897 & 72.5524 & 88.8908 & 60.7870 \\
\hline Bureaucratic Quality & 0.0386 & 0.0269 & 66.4678 & 57.8905 & 63.0384 & 71.9994 & 82.6119 & 61.2656 \\
\hline Democracy & 0.0418 & 0.0285 & 66.7442 & 60.4170 & 59.5747 & 71.4051 & 89.0099 & 63.8751 \\
\hline Corruption & 0.0388 & 0.0178 & 65.9662 & 53.2313 & 64.0316 & 75.3902 & 77.5900 & 61.5484 \\
\hline \multirow[t]{2}{*}{ Law and Order } & 0.0379 & 0.0289 & 64.7331 & 60.7651 & 61.7603 & 72.5803 & 81.7243 & 64.4422 \\
\hline & \multicolumn{8}{|c|}{ Geography } \\
\hline Tropics & 0.0273 & 0.0386 & 58.8520 & 65.9825 & 72.7294 & 62.2215 & 69.3136 & 77.0877 \\
\hline \multirow[t]{2}{*}{ LCR100KM } & 0.0369 & 0.0289 & 56.2770 & 72.9383 & 63.6480 & 71.5072 & 77.8089 & 67.5222 \\
\hline & \multicolumn{8}{|c|}{ Health } \\
\hline \multirow[t]{2}{*}{ Life Expectancy } & 0.0420 & 0.0283 & 60.1857 & 64.6618 & 56.2434 & 73.6292 & 90.0078 & 63.1112 \\
\hline & \multicolumn{8}{|c|}{ Ethnic Fractionalization } \\
\hline Language & 0.0316 & 0.0364 & 60.6060 & 65.8298 & 71.5225 & 60.6811 & 69.7974 & 78.7515 \\
\hline Ethnic Tensions & 0.0360 & 0.0303 & 64.9187 & 59.7555 & 63.0766 & 72.5041 & 80.0978 & 63.8251 \\
\hline \multirow[t]{2}{*}{ Religion Tensions } & 0.0384 & 0.0231 & 65.8978 & 56.0266 & 64.2718 & 72.4871 & 79.8410 & 59.7215 \\
\hline & \multicolumn{8}{|c|}{ Conflict } \\
\hline Internal Conflict & 0.0364 & 0.0217 & 63.0332 & 62.2737 & 64.8217 & 75.5970 & 74.9994 & 67.9374 \\
\hline External Conflict & 0.0363 & 0.0240 & 61.8535 & 66.7947 & 65.2635 & 72.4054 & 75.8261 & 65.8542 \\
\hline
\end{tabular}




\section{Table 5: Threshold Regressions}

This table presents regression coefficient estimates for threshold regression models using threshold variable $q_{i}$ in equation (4.6). Panels (1)-(21) report the results for various threshold variables grouped by growth theory. The significance of the corresponding threshold effect is noted with star. Each panel refers to a threshold regression based on the corresponding threshold variable and shows the posterior inclusion probability (PIP), the posterior mean (PM), and the LS coefficient of the full model (Full) for the regression coefficients of Life Expectancy, Openness, and Debt in the low and high regimes. All models included a constant and a trend. $* * *, * *$, and $*$ denote significance at $1 \%, 5 \%$, and $10 \%$, respectively.

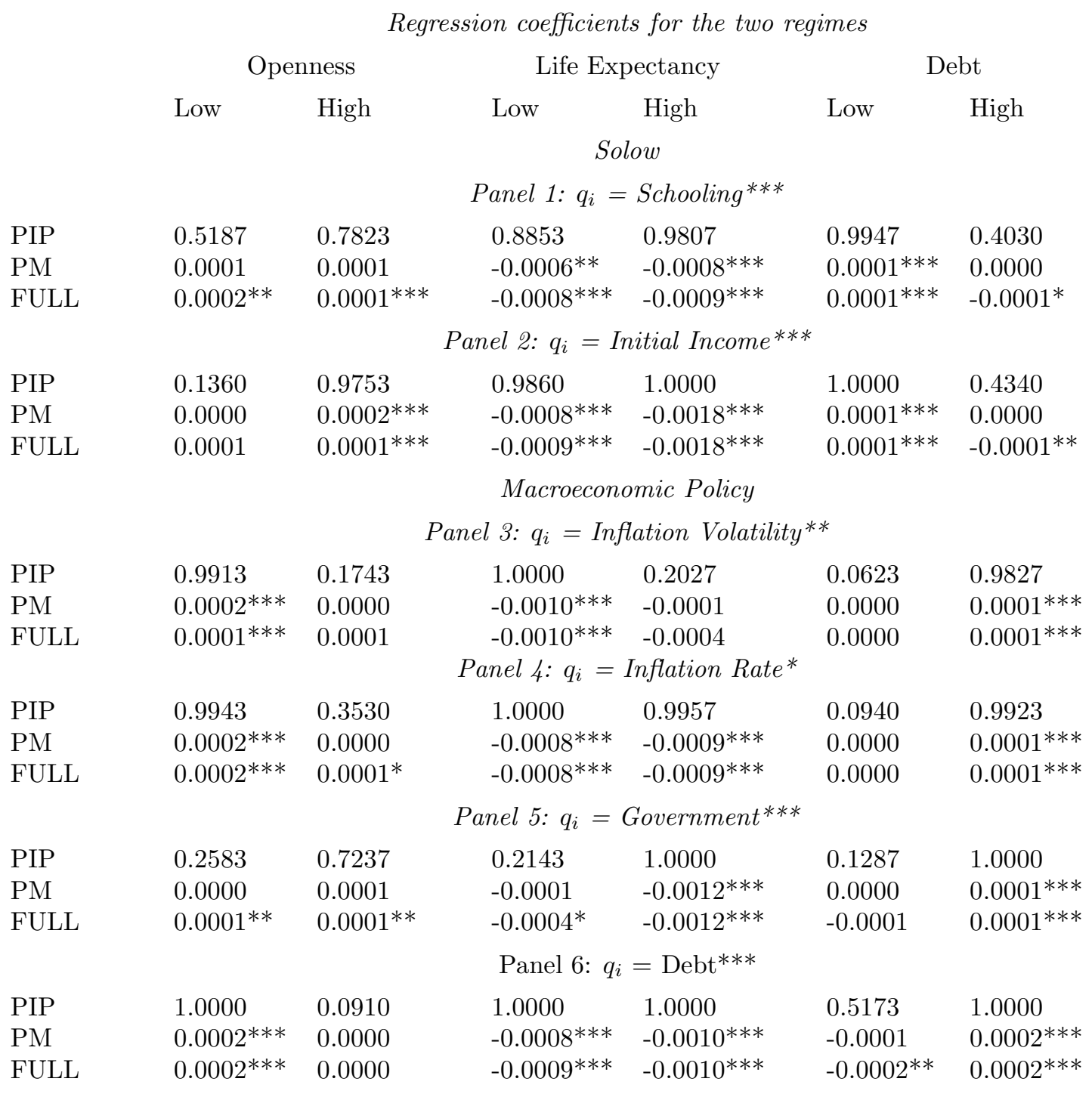

Table continued on next page ... 


\section{Table 5 continued}

Regression coefficients for the two regimes

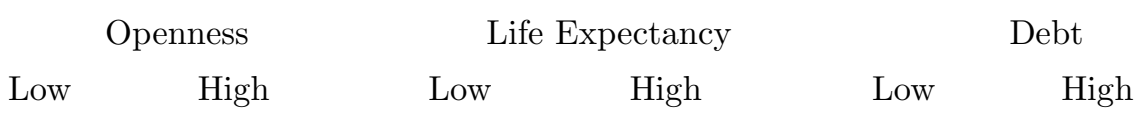

Financial Development

Panel \%: $q_{i}=B C B D^{* * *}$

\begin{tabular}{lllllll} 
PIP & 0.1530 & 1.0000 & 0.8700 & 1.0000 & 0.9693 & 0.5530 \\
PM & 0.0000 & $0.0002^{* * *}$ & $-0.0010^{*}$ & $-0.0007^{* * *}$ & $0.0001^{* * *}$ & 0.0000 \\
FULL & 0.0001 & $0.0002^{* * *}$ & $-0.0012^{* * *}$ & $-0.0008^{* * *}$ & $0.0001^{* * *}$ & $-0.0001^{* * *}$ \\
& & \multicolumn{7}{c}{ Panel $8: q_{i}=D B A C B A^{* * *}$} \\
PIP & 0.0820 & 1.0000 & 0.9037 & 1.0000 & 1.0000 & 0.3193 \\
PM & 0.0000 & $0.0002^{* * *}$ & $-0.0006^{* *}$ & $-0.0012^{* * *}$ & $0.0001^{* * *}$ & 0.0000 \\
FULL & 0.0000 & $0.0002^{* * *}$ & $-0.0006^{* * *}$ & $-0.0012^{* * *}$ & $0.0001^{* * *}$ & $-0.0001^{*}$
\end{tabular}

Institutions

Panel 9: $q_{i}=$ Executive Constraints***

\begin{tabular}{|c|c|c|c|c|c|c|}
\hline PIP & 0.5237 & 0.8103 & 0.9800 & 0.9630 & 0.9943 & 0.6213 \\
\hline PM & 0.0001 & 0.0001 & $-0.0009^{* * *}$ & $-0.0007^{* * *}$ & $0.0001 * * *$ & -0.0001 \\
\hline \multirow[t]{2}{*}{ FULL } & $0.0002^{* *}$ & $0.0001^{* *}$ & $-0.0010^{* * *}$ & $-0.0008^{* * *}$ & $0.0001^{* * *}$ & $-0.0001^{* *}$ \\
\hline & \multicolumn{6}{|c|}{ Panel 10: $q_{i}=$ Bureaucratic Quality ${ }^{* * *}$} \\
\hline PIP & 0.0747 & 1.0000 & 0.4587 & 1.0000 & 1.0000 & 0.3960 \\
\hline PM & 0.0000 & $0.0003^{* * *}$ & -0.0002 & $-0.0012^{* * *}$ & $0.0001 * * *$ & 0.0000 \\
\hline \multirow[t]{2}{*}{ FULL } & 0.0000 & $0.0002^{* * *}$ & $-0.0004^{*}$ & $-0.0013^{* * *}$ & $0.0001 * * *$ & $-0.0001^{*}$ \\
\hline & \multicolumn{6}{|c|}{ Panel 11: $q_{i}=$ Democracy ${ }^{* * *}$} \\
\hline PIP & 0.5730 & 0.7700 & 0.9577 & 0.9920 & 0.9983 & 0.5407 \\
\hline PM & 0.0001 & 0.0001 & $-0.0009^{* * *}$ & $-0.0008^{* * *}$ & $0.0001 * * *$ & 0.0000 \\
\hline \multirow[t]{2}{*}{ FULL } & $0.0002^{* *}$ & $0.0001^{* * *}$ & $-0.0010^{* * *}$ & $-0.0008^{* * *}$ & $0.0001^{* * *}$ & $-0.0001^{* *}$ \\
\hline & \multicolumn{6}{|c|}{ Panel 12: $q_{i}=$ Corruption ${ }^{* * *}$} \\
\hline PIP & 0.6137 & 0.1880 & 0.9517 & 0.1537 & 0.9893 & 0.0577 \\
\hline PM & 0.0001 & 0.0000 & $-0.0006^{* * *}$ & 0.0000 & $0.0001^{* * *}$ & 0.0000 \\
\hline \multirow[t]{2}{*}{ FULL } & $0.0001^{* * *}$ & 0.0001 & $-0.0006^{* * *}$ & -0.0004 & $0.0001^{* * *}$ & 0.0000 \\
\hline & \multicolumn{6}{|c|}{ Panel 13: $q_{i}=$ Law and Order*** } \\
\hline PIP & 0.5813 & 0.1317 & 0.3180 & 1.0000 & 0.9820 & 0.0650 \\
\hline PM & 0.0001 & 0.0000 & -0.0001 & $-0.0020 * * *$ & $0.0001 * * *$ & 0.0000 \\
\hline FULL & $0.0002^{* * *}$ & 0.0001 & $-0.0004^{*}$ & $-0.0020^{* * *}$ & $0.0001^{* * *}$ & 0.0000 \\
\hline
\end{tabular}

Table continued on next page ... 


\section{Table 5 continued}

\begin{tabular}{|c|c|c|c|c|c|c|}
\hline \multirow[b]{2}{*}{ PIP } & \multicolumn{6}{|c|}{ Geography and Climate } \\
\hline & 0.1010 & 0.5350 & 1.0000 & 0.3687 & 0.0910 & 0.9923 \\
\hline PM & 0.0000 & 0.0001 & $-0.0015^{* * *}$ & -0.0002 & 0.0000 & $0.0001^{* * *}$ \\
\hline \multirow[t]{2}{*}{ FULL } & 0.0000 & $0.0002^{* * *}$ & $-0.0016^{* * *}$ & $-0.0005^{* *}$ & 0.0000 & $0.0001^{* * *}$ \\
\hline & \multicolumn{6}{|c|}{ Panel 15: $q_{i}=L C R 100 K M^{* * *}$} \\
\hline PIP & 0.0843 & 1.0000 & 0.9810 & 1.0000 & 1.0000 & 0.0650 \\
\hline PM & 0.0000 & $0.0002^{* * *}$ & $-0.0006^{* * *}$ & $-0.0011^{* * *}$ & $0.0001^{* * *}$ & 0.0000 \\
\hline \multirow[t]{3}{*}{ FULL } & 0.0001 & $0.0002^{* * *}$ & $-0.0006^{* * *}$ & $-0.0012^{* * *}$ & $0.0001^{* * *}$ & 0.0000 \\
\hline & \multicolumn{6}{|c|}{ Ethnic Fractionalization } \\
\hline & \multicolumn{6}{|c|}{ Panel 16: $q_{i}=$ Language $^{* *}$} \\
\hline PIP & 0.9810 & 0.6687 & 0.9967 & 1.0000 & 0.8250 & 0.3057 \\
\hline PM & $0.0002^{* * *}$ & 0.0001 & $-0.0010^{* * *}$ & $-0.0012^{* * *}$ & 0.0001* & 0.0000 \\
\hline \multirow[t]{2}{*}{ FULL } & $0.0002^{* * *}$ & $0.0002^{* *}$ & $-0.0010^{* * *}$ & $-0.0012^{* * *}$ & $0.0001^{* * *}$ & 0.0001 \\
\hline & \multicolumn{6}{|c|}{ Panel 17: $q_{i}=$ Ethnic Tensions*** } \\
\hline PIP & 1.0000 & 0.0887 & 1.0000 & 1.0000 & 0.5567 & 0.0643 \\
\hline PM & $0.0003^{* * *}$ & 0.0000 & $-0.0009^{* * *}$ & $-0.0022^{* * *}$ & 0.0000 & 0.0000 \\
\hline \multirow[t]{2}{*}{ FULL } & $0.0003^{* * *}$ & 0.0000 & $-0.0008^{* * *}$ & $-0.0022^{* * *}$ & $0.0001^{* *}$ & 0.0000 \\
\hline & \multicolumn{6}{|c|}{ Panel 18: $q_{i}=$ Religion Tensions $* *$} \\
\hline PIP & 0.9323 & 0.2413 & 1.0000 & 0.7463 & 0.9173 & 0.1160 \\
\hline $\mathrm{PM}$ & $0.0001^{* *}$ & 0.0000 & $-0.0009^{* * *}$ & -0.0004 & $0.0001^{* *}$ & 0.0000 \\
\hline \multirow[t]{3}{*}{ FULL } & $0.0002^{* * *}$ & 0.0001 & $-0.0009 * * *$ & $-0.0006^{* *}$ & $0.0001^{* * *}$ & 0.0000 \\
\hline & \multicolumn{6}{|c|}{ Health } \\
\hline & \multicolumn{6}{|c|}{ Panel 19: $q_{i}=$ Life Expectancy*** } \\
\hline PIP & 0.4327 & 0.6313 & 0.9147 & 1.0000 & 0.9920 & 0.2093 \\
\hline PM & 0.0001 & 0.0001 & $-0.0010^{* *}$ & $-0.0018^{* * *}$ & $0.0001^{* * *}$ & 0.0000 \\
\hline \multirow[t]{3}{*}{ FULL } & $0.0002^{*}$ & $0.0001^{* *}$ & $-0.0012^{* * *}$ & $-0.0018^{* * *}$ & $0.0001^{* * *}$ & $-0.0001^{*}$ \\
\hline & \multicolumn{6}{|c|}{ Conflict } \\
\hline & \multicolumn{6}{|c|}{ Panel 20: $q_{i}=$ Internal Conflict ${ }^{* *}$} \\
\hline PIP & 0.9983 & 0.1217 & 1.0000 & 1.0000 & 0.7600 & 0.1017 \\
\hline PM & $0.0002^{* * *}$ & 0.0000 & $-0.0007^{* * *}$ & $-0.0037^{* * *}$ & 0.0000 & 0.0000 \\
\hline \multirow[t]{2}{*}{ FULL } & $0.0002^{* * *}$ & 0.0000 & $-0.0007^{* * *}$ & $-0.0037^{* * *}$ & $0.0001^{* * *}$ & 0.0000 \\
\hline & \multicolumn{6}{|c|}{ Panel 21: $q_{i}=$ External Conflict ${ }^{* * *}$} \\
\hline PIP & 0.8110 & 0.9160 & 1.0000 & 0.9140 & 0.9930 & 0.7023 \\
\hline PM & 0.0001 & $0.0002^{* *}$ & $-0.0008^{* * *}$ & $-0.0010^{* *}$ & $0.0001^{* * *}$ & -0.0001 \\
\hline FULL & $0.0001 * * *$ & $0.0002^{* * *}$ & $-0.0007^{* * *}$ & $-0.0011^{* * *}$ & $0.0001^{* * *}$ & $-0.0002^{* *}$ \\
\hline
\end{tabular}




\section{Table A1: Data Appendix}

\section{Variable}

Time trend

Growth Volatility

Initial Income

Population Growth

Investments

Schooling

Time trend variable for the periods 1985-89, 1990-94, 1995-99, 2000-04 and 2005-09.

Standard deviation of the growth rate of real per capita GDP for the periods 1985-89, 1990-94, 1995-99, 2000-04 and 2005-09. Source: PWT 7.0.

Logarithm of per capita GDP in chain series at 1985, 1990, 1995, 2000, 2005 (lag values over the periods 1980, 1985, 1990, 1995, 2000). Source: PWT 7.0.

Logarithm of average population growth rates plus 0.05 for the periods 1985-89, 1990-94, 1995-99, 2000-04 and 2005-09 (lag values over the periods 1980-84, 1984-99, 1990-94, 1995-99 and 2000-04) Source: PWT 7.0

Logarithm of average ratios over each period of investment to GDP for the periods 1985-89, 199094, 1995-99, 2000-04 and 2005-09 (lag values over the periods 1980-84, 1984-99, 1990-94, 1995-99 and 2000-04). Source: PWT 7.0

Logarithm of average years of male secondary and tertiary school attainment $(25+)$ in 1985, 1990, 1995 and 1999 (lag values over the periods 1980, 1985, 1990, 1995). Source: Barro and Lee (2013).

Debt

Public debt to GDP for the periods 1985-89, 1990-94, 1995-99, 2000-04 and 2005-09 (lag values over the periods 1980-84, 1984-99, 1990-94, 1995-99 and 2000-04). Source:IMF, Debt Database Fall 2011 Vintage.

Government $\quad$ Log of average ratios for each period of government consumption (net of outlays on defense and education) to GDP for the periods 1985-89, 1990-94, 1995-99, 2000-04 and 2005-09 (lag values over the periods 1980-84, 1984-99, 1990-94, 1995-99 and 2000-04). Source: PWT 7.0

Inflation Rate Log average inflation for the periods 1985-89, 1990-94, 1995-99, 2000-04 and 2005-09 (lag values over the periods 1980-84, 1984-99, 1990-94, 1995-99 and 2000-04). Source: Worldbank.

Inflation Volatility Standard deviation of inflation for the periods for the periods 1985-89, 1990-94, 1995-99, 2000-04 and 2005-09 (lag values over the periods 1980-84, 1984-99, 1990-94, 1995-99 and 2000-04). Source: Worldbank.

Openness $\quad$ Average ratios for each period of exports plus imports to GDP for the periods for the periods 198589, 1990-94, 1995-99, 2000-04 and 2005-09 (lag values over the periods 1980-84, 1984-99, 1990-94, 1995-99 and 2000-04). Source: PWT 7.0

Table continued on next page ... 
Table A1 continued

\section{Variable}

BCBD

DBACBA

\section{Description}

Private credit by deposit money banks as a share of demand, time and saving deposits in deposit money banks. Averages for the periods for the periods 1985-89, 1990-94, 1995-99, 2000-04 and 2005-09 (lag values over the periods 1980-84, 1984-99, 1990-94, 1995-99 and 2000-04). Source: Beck, Demirgüç-Kunt, and Levine (2009).

Ratio of deposit money bank claims on domestic nonfinancial real sector to the sum of deposit money bank and Central Bank claims on domestic nonfinancial real sector. Averages for the periods 1985-89, 1990-94, 1995-99, 2000-04 and 2005-09 (lag values over the periods 1980-84, 198499, 1990-94, 1995-99 and 2000-04). Source: Beck, Demirgüç-Kunt, and Levine (2009).

Executive Constraints A measure of the extent of institutionalized constraints on the decision making powers of chief executives. This variable ranges from zero to one where higher values equal a greater extent of institutionalized constraints on the power of chief executives. Averages for the periods 198589, 1990-94, 1995-99, 2000-04 and 2005-09 (lag values over the periods 1980-84, 1984-99, 1990-94, 1995-99 and 2000-04). Source: Polity IV, http://www.systemicpeace.org/polity/polity4.htm

Political Stability

Political stability is measured as the average of the first differences (in absolute values) of the Polity2 variable from Polity IV. The Polity2 variable is a measure of the degree of democracy in a country with a score of +10 representing most democratic and -10 signifying most autocratic. Averages for the periods for the periods 1985-89, 1990-94, 1995-99, 2000-04 and 2005-09 (lag values over the periods 1980-84, 1984-99, 1990-94, 1995-99 and 2000-04). Higher values indicate more political instability. Source: Polity IV, http://www.systemicpeace.org/polity/polity4.htm.

Table continued on next page ... 


\section{Table A1 continued}

\section{Variable}

Law and Order

Corruption

\section{Description}

PRS assesses Law and Order, separately. The Law subcomponent is an assessment of the strength and impartiality of the legal system, while the Order subcomponent is an assessment of popular observance of the law. Higher score means lower risk. Averages for the periods 1985-89, 1990-94, 1995-99, 2000-04 and 2005-09 (lag values over the periods 1980-84, 1984-99, 1990-94, 1995-99 and 2000-04). The max value for this variable is 1 . Source: International Country Risk Guide.

The PRS measure of the corruption within the political system reflects actual or potential corruption in the form of excessive patronage, nepotism, job reservations, "favor-for-favors", secret party funding, and suspiciously close ties between politics and business. In PRSs view these sorts of corruption pose risk to foreign business, potentially leading to popular discontent, unrealistic and inefficient controls on the state economy, and encourage the development of the black market. This variable ranges from zero to one and higher values mean less risk of corruption. Averages for the periods for the periods 1985-89, 1990-94, 1995-99, 2000-04 and 2005-09 (lag values over the periods 1980-84, 1984-99, 1990-94, 1995-99 and 2000-04). Source: International Country Risk Guide.

Bureaucratic Quality PRSs bureaucratic quality index gives high points to countries where the bureaucracy has the strength and expertise to govern without drastic changes in policy or interruptions in government services. In these low risk countries, the bureaucracy tends to be somewhat autonomous from political pressure and to have an established mechanism for recruitment and training. Countries that lack the cushioning effect of a strong bureaucracy receive low points because a change in government tends to be traumatic in terms of policy formulation and day-to-day administrative functions. This variable ranges from zero to one. Averages for the periods for the periods 198589, 1990-94, 1995-99, 2000-04 and 2005-09 (lag values over the periods 1980-84, 1984-99, 1990-94, 1995-99 and 2000-04). Source: International Country Risk Guide.

Table continued on next page ... 


\section{Table A1 continued}

\section{Variable}

Democracy

Tropics

LCR100KM

External Conflict

\section{Description}

Level of institutionalized democracy. This variable ranges from zero to ten where higher values equal a greater extent of institutionalized democracy. Averages for the periods 1985-89, 1990-94, 1995-99, 2000-04 and 2005-09 (lag values over the periods 1980-84, 1984-99, 1990-94, 1995-99 and 2000-04). Source : Polity IV.

Percentage of land area classified as tropical and subtropical via the in Koeppen-Geiger system. Source: The Center for International Development at Harvard University

Percentage of a countrys land area within 100km of an ice- free coast. Source: The Center for International Development at Harvard University.

The external conflict measure is an assessment of the risk to both the incumbent government and inward investment. It ranges from trade restrictions and embargoes, whether imposed by a single country, a group of countries, or the whole international community, through geopolitical disputes, armed threats, exchanges of fire on borders, border incursions, foreign-supported insurgency, and full-scale warfare. Higher values of External Conflict mean lower risk. Averages for the periods 1985-89, 1990-94, 1995-99, 2000-04 and 2005-09 (lag values over the periods 1980-84, 1984-99, 199094, 1995-99 and 2000-04). The max value for this variable is 1 . Source: International Country Risk Guide.

Internal Conflict This is an assessment of political violence in the country and its actual or potential impact on governance. The highest rating is given to those countries where there is no armed opposition to the government and the government does not indulge in arbitrary violence against its own people. The lowest rating is given to a country embroiled in an on-going civil war. Averages for the periods 1985-89, 1990-94, 1995-99, 2000-04 and 2005-09 (lag values over the periods 1980-84, 1984-99, 199094, 1995-99 and 2000-04). The max value for this variable is 1. Source: International Country Risk Guide.

Table continued on next page ... 


\section{Table A1 continued}

\section{Variable \\ Description}

Religion Tensions Religious tensions may stem from the domination of society and/or governance by a single religious group that seeks to replace civil law by religious law and to exclude other religions from the political and/or social process; the desire of a single religious group to dominate governance; the suppression of religious freedom; the desire of a religious group to express its own identity, separate from the country as a whole. Higher score means lower risk. Averages for the periods 1985-89, 1990-94, 1995-99, 2000-04 and 2005-09 (lag values over the periods 1980-84, 1984-99, 1990-94, 1995-99 and 2000-04). The max value for this variable is 1 . Source: International Country Risk Guide.

Ethnic Tensions This component measures the degree of tension within a country attributable to racial, nationality, or language divisions. Lower ratings are given to countries where racial and nationality tensions are high because opposing groups are intolerant and unwilling to compromise. Higher ratings are given to countries where tensions are minimal, even though such differences may still exist. Averages for the periods 1985-89, 1990-94, 1995-99, 2000-04 and 2005-09 (lag values over the periods 1980-84, 1984-99, 1990-94, 1995-99 and 2000-04). The max value for this variable is 1. Source: International Country Risk Guide.

Language

Measure of linguistic fractionalization based on data describing shares of languages spoken as "mother tongues". Source: Alesina, Devleeschauwer, Easterly, Kurlat, and Wacziarg (2003).

Life Expectancy Average life expectancy for the periods 1985-89, 1990-94, 1995-99, 2000-04, and 2005-09 (lag values over the periods 1980-84, 1984-99, 1990-94, 1995-99 and 2000-04). Source: World Bank. 


\section{Table A2: Countries for Ethnic Tensions Regimes}

Country

Regime $1 \leq 0.8028$

Regime $2>0.8028$

Algeria

Argentina

Australia

Austria

Bangladesh

Belgium

Bolivia

Brazil

Cameroon

Canada

Chile

China

Colombia

Congo Republic

Costa Rica

Cote d'Ivoire

Cyprus

Denmark

Dominican Republic

Ecuador

Egypt

Finland

France

Gabon

Gambia

Ghana

Greece

Guatemala

Guyana

Honduras

Hungary

India

Indonesia

Iran

Ireland

Israel

Italy

Jamaica

Japan

Jordan

Korea Republic

Malawi

Malaysia

Mali

Morocco

Netherlands

New Zealand

Niger

Norway

Pakistan

Panama

Papua New Guinea

Paraguay

Peru

Philippines

Portugal

Senegal

Sierra Leone

South Africa

Spain

Sri Lanka

Sweden

Syria

Thailand

Togo

Trinidad \& Tobago

Tunisia

Turkey

United Kingdom

United States

Uruguay

Venezuela

$1985-89 \quad 1990-94 \quad 1995-99 \quad 2000-04 \quad 2005-09 \quad 1985-89 \quad 1990-1994 \quad 1995-99 \quad 2000-05 \quad 2005-09$

\begin{tabular}{|c|c|c|c|c|}
\hline $\mathrm{x}$ & $\mathrm{x}$ & $\mathrm{x}$ & $\mathrm{x}$ & $\mathrm{x}$ \\
\hline & & & $\mathrm{x}$ & $\mathrm{x}$ \\
\hline & & & $x$ & $\mathrm{x}$ \\
\hline $\mathrm{x}$ & $\mathrm{x}$ & $\mathrm{x}$ & $\mathrm{x}$ & $\mathrm{x}$ \\
\hline$x$ & $\mathrm{x}$ & $\mathrm{x}$ & $\mathrm{x}$ & $\mathrm{x}$ \\
\hline $\mathrm{x}$ & $\mathrm{x}$ & $\mathrm{x}$ & $\mathrm{x}$ & $\mathrm{x}$ \\
\hline & & & $\mathrm{x}$ & $\mathrm{x}$ \\
\hline $\mathrm{x}$ & $\mathrm{x}$ & $\mathrm{x}$ & $\mathrm{x}$ & $\mathrm{x}$ \\
\hline & & $\mathrm{x}$ & $\mathrm{x}$ & $\mathrm{x}$ \\
\hline & $x$ & $\mathrm{x}$ & $\mathrm{x}$ & $\mathrm{x}$ \\
\hline $\mathrm{x}$ & $\mathrm{x}$ & $\mathrm{x}$ & $\mathrm{x}$ & $\mathrm{x}$ \\
\hline $\mathrm{x}$ & $\mathrm{x}$ & $\mathrm{x}$ & $\mathrm{x}$ & $\mathrm{x}$ \\
\hline $\mathrm{x}$ & $\mathrm{x}$ & $\mathrm{x}$ & $\mathrm{x}$ & $\mathrm{x}$ \\
\hline $\mathrm{x}$ & $\mathrm{x}$ & $\mathrm{x}$ & $\mathrm{x}$ & $\mathrm{x}$ \\
\hline $\mathrm{x}$ & $\mathrm{x}$ & $\mathrm{x}$ & $\mathrm{x}$ & $\mathrm{x}$ \\
\hline $\mathrm{x}$ & $\mathrm{x}$ & $\mathrm{x}$ & & \\
\hline $\mathrm{x}$ & $\mathrm{x}$ & $\mathrm{x}$ & $\mathrm{x}$ & $\mathrm{x}$ \\
\hline $\mathrm{x}$ & $\mathrm{x}$ & $\mathrm{x}$ & $\mathrm{x}$ & $\mathrm{x}$ \\
\hline $\mathrm{x}$ & $\mathrm{x}$ & $\mathrm{x}$ & & \\
\hline $\mathrm{x}$ & $\mathrm{x}$ & $\mathrm{x}$ & $\mathrm{x}$ & $\mathrm{x}$ \\
\hline $\mathrm{x}$ & $\mathrm{x}$ & $\mathrm{x}$ & $\mathrm{x}$ & $\mathrm{x}$ \\
\hline $\mathrm{x}$ & $\mathrm{x}$ & $\mathrm{x}$ & $\mathrm{x}$ & $\mathrm{x}$ \\
\hline & & & & $\mathrm{x}$ \\
\hline $\mathrm{x}$ & $\mathrm{x}$ & $\mathrm{x}$ & $\mathrm{x}$ & $\mathrm{x}$ \\
\hline $\mathrm{x}$ & $\mathrm{x}$ & $\mathrm{x}$ & $\mathrm{x}$ & $\mathrm{x}$ \\
\hline $\mathrm{x}$ & $\mathrm{x}$ & $\mathrm{x}$ & & $\mathrm{x}$ \\
\hline $\mathrm{x}$ & $\mathrm{x}$ & & & \\
\hline $\mathrm{x}$ & $\mathrm{x}$ & $x$ & $\mathrm{x}$ & $\mathrm{x}$ \\
\hline $\mathrm{x}$ & $\mathrm{x}$ & $\mathrm{x}$ & & \\
\hline & & $x$ & & \\
\hline $\mathrm{x}$ & $\mathrm{x}$ & $\mathrm{x}$ & $\mathrm{x}$ & $\mathrm{x}$ \\
\hline $\mathrm{x}$ & $\mathrm{x}$ & $\mathrm{x}$ & & $\mathrm{x}$ \\
\hline$x$ & $\mathrm{x}$ & $\mathrm{x}$ & $\mathrm{x}$ & $\mathrm{x}$ \\
\hline$x$ & $\mathrm{x}$ & $\mathrm{x}$ & $\mathrm{x}$ & $\mathrm{x}$ \\
\hline $\mathrm{x}$ & $\mathrm{x}$ & $\mathrm{x}$ & & \\
\hline & & & $\mathrm{x}$ & $\mathrm{x}$ \\
\hline $\mathrm{x}$ & $\mathrm{x}$ & $\mathrm{x}$ & $\mathrm{x}$ & $\mathrm{x}$ \\
\hline & $\mathrm{x}$ & $\mathrm{x}$ & $\mathrm{x}$ & $\mathrm{x}$ \\
\hline$x$ & $\mathrm{x}$ & $x$ & $\mathrm{x}$ & $\mathrm{x}$ \\
\hline & $\mathrm{x}$ & $\mathrm{x}$ & $\mathrm{x}$ & $\mathrm{x}$ \\
\hline$x$ & $\mathrm{x}$ & $\mathrm{x}$ & $\mathrm{x}$ & \\
\hline & $\mathrm{x}$ & $x$ & $\mathrm{x}$ & $\mathrm{x}$ \\
\hline & $\mathrm{x}$ & $\mathrm{x}$ & $\mathrm{x}$ & $\mathrm{x}$ \\
\hline & $\mathrm{x}$ & $\mathrm{x}$ & $\mathrm{x}$ & $\mathrm{x}$ \\
\hline & $\mathrm{x}$ & $x$ & $\mathrm{x}$ & $\mathrm{x}$ \\
\hline & $\mathrm{x}$ & $x$ & $\mathrm{x}$ & $\mathrm{x}$ \\
\hline
\end{tabular}

$\mathrm{x}$

$\mathrm{x}$

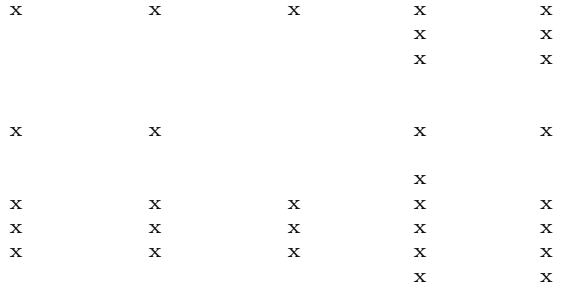

